\title{
LA CARTOGRAFÍA DEL CORPO DI TRUPPE VOLONTARIE, 1937-1939*
}

por

\author{
LUIS URTEAGA \\ FRANCESC NADAL \\ Depto. de Geografía Humana, Universidad de Barcelona \\ José IGNACIO MURO \\ Depto. de Historia y Geografía, Universidad Rovira i Virgili
}

RESUMEN: Este artículo describe la organización y actividades de una sección cartográfica del Istituto Geografico Militare, enviada a España en mayo de 1937 para reforzar los servicios del Corpo di Truppe Volontarie. Entre los mapas compilados por los cartógrafos italianos destaca una colección de sesenta hojas del Mapa topográfico de España a escala 1:50.000, y la edición polícroma de una carta itineraria con tintas bipsométricas a escala 1:200.000, en trece hojas, que cubren un extensión de $197.838 \mathrm{~km} 2$ del territorio peninsular.

PALABRAS Clave: Cartografía militar. Istituto Geografico Militare. Corpo di Truppe Volontarie. Guerra de España (19361939).

ABSTRACT: This paper studies the organization and work of a cartograpbic section of the Istituto Geografico Militare; which was sent to Spain in 1937 in order to reinforce the efficiency of the Corpo di Truppe Volontarie. Among the maps compiled by the Italian cartographers we emphasise a series of 60 sheets of the Topographic Map of Spain at the scale of 1:50.000, and the edition of a medium-scale Road Map (1:200.000), in thirteen sheets, covering an area of 197,838 square kilometres of the Iberian Peninsula.

KEY WORDS: Military cartography. Istituto Geografico Militare. Corpo di Truppe Volontarie. Spanish Civil War (1936-1939).

* Este trabajo se ha realizado en el marco del proyecto de investigación PB96-0226, financiado por la Dirección General de Enseñanza Superior.

Hispania, LXII/1, núm. 210 (2002) 283-298 


\section{INTRODUCCIÓN}

La participación italiana en la guerra civil española ha sido objeto de un persistente esfuerzo historiográfico, que no ha hecho sino crecer en los últimos años. Tras la valiosa síntesis producida por John Coverdale ${ }^{1}$, nuevas líneas de investigación han seguido explorando la dimensión política y militar de la intervención italiana en España. El trabajo de los especialistas en historia internacional ha permitido reconstruir el contexto geopolítico en el que se forjó la alianza entre Mussolini y Franco, y esclarecer el papel de fascismo italiano en la internacionalización de la guerra de España ${ }^{2}$. Los historiadores militares italianos, por su parte, han realizado una meticulosa indagación, sobre fuentes primarias, acerca del carácter y el alcance de la ayuda militar prestada por Italia a Franco ${ }^{3}$. Entre la abundante bibliografía dedicada al tema, sin embargo, nadie ha aludido, hasta donde sabemos, a la labor cartográfica realizada por la Sezione Topocartografica anexa al Corpo di Truppe Volontarie.

Esta omisión no deja de ser sorprendente. En las guerras se emplean mapas; en la española se utilizaron a millones ${ }^{4}$. ¿De qué mapas dispuso el Corpo di Truppe Volontarie? ¿cómo los consiguió? ¿que relaciones mantuvo el servicio cartográfico del ejército italiano con el servicio cartográfico de Franco? Tales son las preguntas que intenta responder este artículo.

La actividad de los cartógrafos militares italianos reviste interés, en primer término, para la historiografía militar de la guerra civil española. Sus mapas tienen importancia también como documentos geográficos. La Sezione Topocartografica utilizó la fotografía aérea para revisar y actualizar la cartografía española a gran escala. La cartografía que estudiamos en este trabajo no ha sido catalogada en su conjunto, y se encuentra muy dispersa; el primer propósito de nuestro estudio es dar noticia de su localización ${ }^{5}$.

1 Coverdale, John F.: Italian Intervention in the Spanish Civil War, Princeton, Princeton University Press, 1975, 455 págs. Trad. cast.: La intervención fascista en la Guerra Civil española, Madrid, Alianza Universidad, 1979, 390 págs.

2 ALPERT, Michael: Aguas peligrosas. Nueva bistoria internacional de la guerra civil española, 19361939, Madrid, Akal, 1998, 250 págs. Preston, Paul: «Mussolini's Spanish Adventure: From Limited Risk to War», en P. PReston y A.L. MACKENZIE, (eds.): The Republic Besieged. Civil War in Spain, 1936-1939, Edimburgo, Edinburgh University Press, 1998, págs. 21-51. PreSTON, Paul: «Italy and Spain in Civil War and World War», en S. BALFOUR y P. PRESTON, (eds.): Spain and the Great Powers in the Twentieh Century, Londres, Routledge, 1999, págs. 151-184.

3 RovighI, Alberto y STEFANI, Filippo: La partecipazione italiana alla Guerra Civile Spagnola (1936-1939), Roma, Stato Maggiore dell'Esercito. Ufficio Storico, 1992-1993, 4 vols. (vols. I y II, Testo; vols. I y II, Documenti e Allegati). PEDRIALI, Ferdinando: Guerra di Spagna e aviazione italiana, Roma, Aeronautica Militare Italiana-Ufficio Storico, 1992.

4 Vid. NADAL, Francesc; URTEAGA, Luis y MURO: José Ignacio, «Los mapas impresos durante la guerra civil española», (en preparación).

5 La identificación de los mapas editados por el Corpo di Truppe Volontarie puede realizarse a partir de los siguientes gráficos de distribución: COMANDO TRUPPE VOLONTARIE, Quadro d'unione dei 


\section{LA SEZIONE TOPOCARTOGRAFICA DEL CORPo dI TRUPPE VolONTARIE}

Entre diciembre de 1936 y febrero de 1937 Mussolini envió a España un contingente próximo a los 50.000 hombres. La fuerza expedicionaria estaba compuesta por tropas regulares del ejército italiano (cerca de 20.000 soldados con sus jefes y oficiales), milicianos fascistas, y un nutrido grupo de «voluntarios» reclutados en el depauperado sur de Italia con la promesa de una paga generosa. Aquella abigarrada tropa, que recibió el nombre de Corpo di Truppe Volontarie, destacaba, más que por su experiencia, por su poderoso equipamiento. El equipo transportado desde Italia ocupó sesenta y dos barcos: incluía 542 piezas de artillería, 105.000 fusiles, dos millones de bombas de mano, 140 millones de cartuchos y cerca de 4.000 vehículos $^{6}$. Faltaban, sin embargo, los mapas necesarios para planificar y dirigir las operaciones militares.

Las fuerzas del general Franco no disponían, a finales de 1936, ni de mapas ni de un servicio cartográfico que pudiera producirlos 7 . Los militares insurrectos habían preparado un golpe de estado, no una guerra. El fracaso de la insurrección en Madrid había dejado en manos de la República las principales insti-

quadrante pubblicati, Vitoria, Sezione Topocartografica, 1937. ComANDo TruPPE VolonTARIE, Fronte di Aragona. Dotazione cartografica. Scala 1:50.000. Serie A (Nord Ebro), Vitoria, Sezione Topocartografica, 1938. Commando Truppe Volontarie, Fronte di Aragona. Dotazione cartografica. Scala 1:50.000. Serie B (Sud Ebro), Vitoria, Sezione Topocartografica, 1938. ComANDo TRUPPE VolonTARIE, Fronte di Aragona. Dotazione cartografica. Scala 1:50.000. Serie C, Vitoria, Sezione Topocartografica, 1938. COMANDO TRUPPE VOLONTARIE, Quadro d'unione delle carte pubblicate. Fronte d'Aragona, Vitoria, Sezione Topocartografica, 1938. COMANDO TRUPPE VOLONTARIE, Quadro d'unione delle carte pubblicate. Fronte di Madrid. Fronte d'Aragona. Fronte Extremadura, Vitoria, Sezione Topocartografica, 1939. CORPO DI TRUPPE VOLONTARIE, Quadro d'unione della carta al 200.000, Vitoria, Sezione Topocartografica, 1939. No hemos podido localizar una colección completa de estos mapas en ninguna de las bibliotecas consultadas. La colección más amplia se halla en la cartoteca del Istituto Geografico Militare de Florencia. Las fichas de catalogación de los mapas a escala 1:50.000 y 1:100.000 son las siguientes: Carta della Spagna che comprende riproduzzioni della carta origin. riproduz. di lucidi della carta origin. schizzi e redisegni del Corpo Truppe Volontarie, 1:50.000. Y Carta della Spagna. Riduzione fotomecanica dal 1:50.000, 1:100.000. Hemos encontrado mapas italianos adicionales, no catalogados en Florencia, en la cartoteca del Museo Militar de Montjuich (Barcelona) y en la biblioteca de la Acadèmia de Ciències de Barcelona. Puede consultarse un repertorio completo de los mapas del Corpo di Truppe Volontarie a escala 1:50.000 en el siguiente trabajo: URTEAGA, Luis y NADAL, Francesc: Las series del Mapa Topográfico de España a escala 1:50.000, Madrid, Instituto Geográfico Nacional, (en publicación). El Institut Cartogràfic de Catalunya ha adquirido recientemente un fondo documental que contiene planes de operaciones, mapas, fotografias aéreas, croquis topográficos y otros documentos procedentes de las divisiones legionarias «Frecce Nere» $\mathrm{y}$ «Frecce Azzurre». Para un inventario parcial del citado fondo vid: GALERA, Montserrat: «Guerra i cartografia a Catalunya. Segles XVII-XX», en INSTITUT CARTOGRÀFIC DE CATALUNYA, La cartografia catalana, Barcelona, Institut Cartogràfic de Catalunya, 2000, págs. 117-195.

6 Vid. Preston, Paul: op. cit., 1999. Y también Rovighi, Alberto y Stefani, Filippo: op. cit., 1992-1993.

7 Vid. URTEAGA, Luis y NADAL, Francesc: op. cit., 2000.

Hispania, LXII/1, núm. 210 (2002) 283-298 
tuciones cartográficas españolas: el Depósito de la Guerra y el Instituto Geográfico. El coronel Darío Gazapo Valdés, jefe del Servicio Topográfico y Cartográfico del Ejército al acabar la guerra, trazó esta pintura de los hechos en una conferencia dictada en 1940: «En aquel caos [julio de 1936] tuvimos la desgracia de que Madrid, con todos los servicios centrales de Cartografía, quedase en zona roja, y nos encontramos con que en las Capitanías Generales y en las regiones militares no disponíamos más que de algunas hojas sueltas [del mapa topográfico a escala 1:50.000] que algún oficial había tenido la curiosidad de comprar y algunas otras que se hallaban en poder de los jefes encargados del servicio, pero nada más. La angustia moral de los encargados de suministrar a los Mandos datos cartográficos era indescriptible.... ${ }^{8}$.

El ejército de África contaba, como única cartografía de la Península, con unos cuantos ejemplares del mapa Michelin a escala 1:400.000. Sobre ellos se trazaron los planes para cruzar el Estrecho. Un informe reservado del Cuartel General de Franco describe así la situación en la primera semana de agosto de 1936: «Al pisar el suelo de la Península, el panorama, desde el punto de vista cartográfico no era nada halagüeño. El Ejército Expedicionario de Africa y Sur de España (denominación que recibe el núcleo de tropas pasadas de Marruecos) disponía en su Cuartel General de un oficial de Estado Mayor capacitado técnicamente para aquellos trabajos, pero que no tenía otros medios que un dibujante y escasísimos medios de dibujo. Todo el bagaje cartográfico se reducía a cuatro o cinco ejemplares del Michelin"?

Los mandos del Corpo di Truppe Volontarie estaban al tanto de la carencia casi total de mapas tanto en el frente como en el Cuartel General de Franco. Durante los meses de octubre y noviembre de 1936 el general Mario Roatta (1887-1968), que luego ostentaría el mando de la fuerza expedicionaria italiana, había recorrido diversas líneas del frente, y visitado el cuartel general de Salamanca en un intento de evaluar la situación militar. Desde Salamanca envió diversos informes cifrados al Ministerio de la Guerra en Roma. En un informe del 16 de noviembre de 1936, Roatta hizo una completa descripción de la situación de las fuerzas y de su equipamiento. Su evaluación acerca de la dotación de medios cartográficos es así de clara: «basta dire che non esistevano carte topografiche, e che ancora oggi non esiste nei comandi quasi altra carta che quella automobilistica «Michelin» al $400.000 »^{10}$.

El propio Roatta iba a tener ocasión de comprobar la persistencia de los problemas cartográficos durante los primeros meses de 1937. La orden de ope-

\footnotetext{
8 GAZAPO VALDÉS, Darío: «La cartografía militar», Boletín de la Real Sociedad Geográfica, Madrid, Tomo LXXVII, 1941, págs. 39-40.

9 Cuartel General del Generalísimo, Memoria del Servicio Cartográfico Militar. Campaña 1936-1939. Burgos, Mayo de 1939, Mecanografiado. SGE Madrid.

10 Informe del general Roatta al Ministero della Guerra. Servizio Informazioni Militari. Roma, Salamanca, 16-17 de noviembre de 1936. Reproducido en ROVIGHI, Alberto y STEFANI, Filippo, op. cit.: 1992, I, Documenti e Allegati, pág. 78.
}

Hispania, LXII/1, núm. 210 (2002) 283-298 
raciones para la batalla de Guadalajara, librada por el Corpo di Truppe Volontarie en marzo de 1937, se preparó sobre el ya citado mapa de carreteras Michelin a escala $1: 400.000^{11}$. Por su escala, y por carecer de información topográfica, esta carta era totalmente inadecuada para planificar una batalla como la que iba a mantenerse en el norte de Madrid. El Corpo di Truppe Volontarie desplegó en las proximidades de Sigüenza más de 40.000 hombres, y una importante fuerza mecanizada. Sin embargo, a muchos jefes de batallón no se les entregaron mapas. En una operación concebida según el esquema de «guerra celere» esta increible omisión sólo puede tener una explicación satisfactoria: tales mapas no existían.

Tras la derrota de Guadalajara el Corpo di Truppe Volontarie fue depurado y reorganizado en profundidad. Se cambiaron sus máximos responsables, se reestructuraron las unidades, y se ampliaron los servicios necesarios para mejorar su efectividad. Entre los nuevos servicios agregados a la fuerza expedicionaria italiana figura una Sezione Topocartografica, enviada desde el Istituto Geografico Militare de Florencia en el mes de mayo de 1937. La citada sección fue embarcada en los puertos de Génova y La Spezia en los barcos «Brunner» y «F» dedicados al transporte de tropas y material militar. Desembarcó en España el 17 de mayo de $1937^{12}$.

La Sezione Topocartografica estaba al mando de un veterano cartógrafo del Istituto Geografico Militare: el mayor Pietro Dossola. En 1926, cuando tenía el grado de capitán, Dossola había participado en las operaciones topográficas realizadas por el ejército italiano en Libia ${ }^{13}$. Durante su estancia en España, al frente de la sección cartográfica, ascendería a Teniente coronel.

El grupo enviado a España adoptó precisamente el modelo organizativo ensayado por los italianos en Africa Oriental a partir de 1935. Se trataba de unidades cartográficas de personal relativamente reducido, pero dotadas con los medios necesarios para operar con autonomía en la reproducción de mapas. El objetivo básico era conseguir reproducir sobre el terreno de operaciones cartografía que tuviera una valor esencialmente táctico, prescindiendo del apoyo directo de la central de Florencia.

Los italianos se instalaron en Vitoria a finales de mayo de 1937, y allí permanecieron hasta el final de la guerra, con sede en el edificio del Conservatorio de música de la ciudad. La elección de la capital alavesa como emplazamiento de la sección cartográfica italiana no fue casual. Vitoria sirvió como centro regulador del conjunto de los servicios cartográficos del Ejército franquista, que venían siendo organizados desde la primavera de 1937 por el coronel de Estado

11 COVERDALE, John: op. cit., 1979, pág. 236.

12 Rovighi, Alberto y Stefani, Filippo: op. cit., 1992, I, Documenti e Allagati, 726.

13 TRAVERSI, Carlo: Storia della cartografia coloniale italiana, Roma, Istituto Poligrafico dello Stato, 1964, pág. 107. 
Mayor Darío Gazapo Valdés ${ }^{14}$. Dada la proximidad de la fábricas papeleras guipuzcoanas era relativamente fácil abstecerse de papel. En la propia ciudad de Vitoria, por otra parte, se contaba con empresas especializadas del sector de artes gráficas, como la imprenta de Heraclio Fournier, capaces de efectuar la tirada litográfica de los mapas.

La sección cartográfica italiana estaba compuesta de personal civil y militar, y contaba con tres servicios distintos: topografía y dibujo, grabado y fotografía, y talleres de estampación. El transporte de la maquinaria litográfica, del gabinete fotográfico, y del resto del equipo se demoró casi un mes. El equipo completo, mandado desde Italia, ocupó 24 vagones de ferrocarril ${ }^{15}$.

El personal al mando de Pietro Dossola estaba integrado por tres topógrafos militares (los capitanes Ugo Campini, Gaetano De Meo y Giorgio Di Vechio), dos cartógrafos (los capitanes Andrea Dall'Osso y Alberto Massa) y tres auxiliares (los sargentos Ruggero de Paoli, Maurizio Pippeni y Carlo Naso). A este personal militar se añadía un grupo de operarios civiles, todos ellos procedentes del Istituto Geografico Militare de Florencia: tres dibujantes, dos zincógrafos (grabadores sobre planchas de zinc), dos fotozincógrafos, un maquinista litógrafo y dos fotógrafos. Para funciones auxiliares de fotografía y litografía, los cartógrafos italianos emplearon también a tres soldados españoles.

Los cartógrafos italianos desempeñaron una doble misión: dibujaron y editaron cartografía a diferentes escalas para el Corpo di Truppe Volontarie, e imprimieron mapas para otras unidades del del Ejército franquista. Dado el apremio de las necesidades militares, cabía descartar cualquier tipo de levantamiento cartográfico regular. La Sezione Topocartografica realizó muy contados trabajos topográficos. Cabe señalar, en la fase inicial de su actividad, la medición de una base de triangulación en Villasante (Burgos), efectuada con un teodolito Zeis II e hilos Invar, y el levantamiento, mediante intersecciones, de un reducido sector de terreno en zona republicana, durante la preparación de la ofensiva sobre Santander. Como norma general, los cartógrafos italianos recurrieron a la vía más expeditiva de compilar sus mapas a partir de fuentes cartográficas españolas, que fueron suministradas por los servicios cartográficos del Ejército de Franco.

\section{LA SERIE ITALIANA DEL MAPA TOPOGRÁFICO DE ESPAÑA A ESCALA 1:50.000}

$\mathrm{Al}$ igual que cualquier otra gran unidad militar, el Corpo di Truppe Volontarie precisaba tres tipos distintos de mapas: mapas a gran escala de uso táctico

14 Vid: Cuartel General del Generalísimo, op. cit., 1939. Y también Nadal, Francesc; URTEAGA, Luis y MURO, José Ignacio: op. cit., 2000.

is IstitUTO GeOGRAFICO MilitARE, La Sezione Topocartografica dell' Istituto Geografico Militare in terre di Spagna con el Corpo Truppe Volontarie, Vitoria, maggio 1937-aprile 1939. Anno de la Vittoria, Florencia, Istituto Geografico Militare, 1939, pág. 37.

Hispania, LXII/1, núm. 210 (2002) 283-298 
(1:25.000 ó 1:50.000), mapas de mando para la dirección estratégica (usualmente a escala $1: 100.000$ ) y cartografía itineraria para planificar y efectuar el transporte de equipo y el movimiento de tropas.

En 1936 el Ejército español apenas disponía de cartografía militar de valor táctico para el territorio peninsular. En la práctica, tanto el Ejército republicano como el franquista debieron servirse del Mapa Topográfico de España a escala 1:50.000 (actualmente Mapa Topográfico Nacional) que venía siendo editado por el Instituto Geográfico desde 1875, y que todavía estaba sin concluir en su primera edición ${ }^{16}$. Tras una laboriosa búsqueda, que incluyó la colaboración alemana, el servicio cartográfico de Franco consiguió una reproducción litográfica en negro de las hojas publicadas por el Instituto Geográfico hasta 1936, que cubrían aproximadamente la mitad del territorio peninsular. Sobre la base de una de aquellas copias monocromas, complementada con otros documentos cartográficos obtenidos, esencialmente, a partir de la incautación de los fondos de la Confederación Hidrográfica del Ebro, la Sezione Topocartografica pudo realizar sus trabajos de compilación.

El Mapa Topográfico de España tiene la misma escala y proyección que la carta topográfica italiana (Carta topografica d'Italia alla scala 1:50.000), con la que estaban familiarizados los oficiales del Corpo di Truppe Volontarie. A diferencia del mapa español, sin embargo, la carta italiana emplea para fines militares una retícula geográfica dividida en minutos, con designación marginal de las cuadrículas mediante letras. En los mapas españoles, por entonces, no había retícula militar sobrepuesta. Esta carencia, unida a mala legibilidad del mapa español cuando se reproduce en negro, debido a la abundante información sobre usos del suelo, inclinó a los responsables de la Sezione Topocartografica a redibujar por completo un cierto número de hojas del Mapa de España 1:50.000.

Las hojas redibujadas tienen un aspecto claro y legible, y ofrecen la impresión neta de un mapa de estilo «italiano». El dibujo refuerza la representación de las vías de comunicación, clasificadas de acuerdo a la norma de signos convencionales del Istituto Geografico Militare de Florencia. La planimetría elimina la indicación de algunos usos del suelo, reteniendo sólo los correspondientes a zonas arboladas. La altimetría se representa mediante curvas de nivel equidistantes 20 metros. La rotulación se hizo con el tipo de letra usual en la carta topográfica italiana.

La información marginal es abundante. En el margen inferior se incluye una completa tabla de signos convencionales en italiano (ver figura 1). En el margen superior se consigna el número de la hoja y su identificación nominal. Los cartógrafos italianos se mostraron extrañamente caprichosos con los nombres de los mapas. La hoja 59 (Villacarriedo), publicada por el Instituto Geográfico en 1935, fue rebautizada con el nombre de "Selaya». La hoja 60 (Valmaseda), que estaba inédita, tomó la denominación de «Ramales»; la 109

16 Vid: URTEAGA, Luis y NADAL, Francesc: op. cit., 2000. 
(Villarcayo) pasó a llamarse «Soncillo»; la 492 (Segura de los Baños), se imprimió como «Barrachina», y así en media docena más de casos. La impresión es monocroma, excepto en la hoja denominada «Madrid e dintorni» que se realizó a cinco colores.

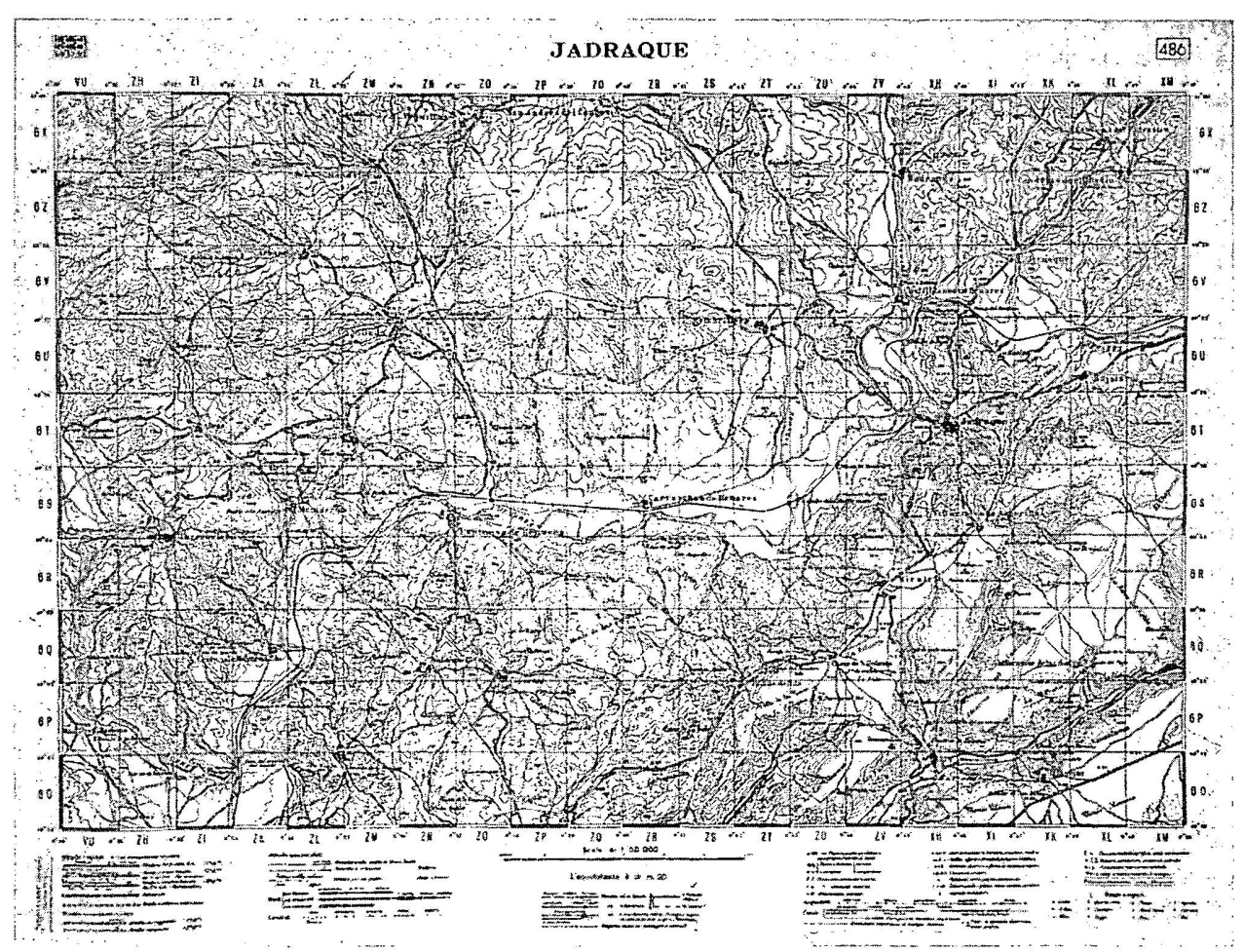

Figura 1. Edición italiana de la hoja n 486 del Mapa de España escala 1:50.000 (Jadraque). Fue redibujado por la Sezione Topocartografica a partir de la primera edición española efectuada por el Instituto Geográfico en 1920.

Fuente: Cortesía del Istituto Geografico Militare. Florencia.

El trabajo de delineación sirvió para revisar y actualizar la planimetría. En algunas hojas, por ejemplo la correspondiente a Brihuega (511), la revisión se efectuó a partir de fotografías aéreas. En todos los mapas se sobrepuso la cuadrícula geográfica ortogonal, típica de la cartografía militar italiana. Algunas de las hojas de la serie que estamos glosando fueron utilizadas también por las tropas españolas. Para facilitar su manejo se sobrepuso una segunda cuadrícula, impresa en rojo, con división kilométrica (por ejemplo en la hoja 108: Las Rozas).

La Sezione Topocartografica redibujó y publicó un total de 60 hojas con las características citadas. Por su distribución geográfica se dividen en tres grupos

Hispania, LXII/1, núm. 210 (2002) 283-298 
correspondientes al frente de Santander, al de Madrid y al de Aragón. Las primeras hojas impresas corresponden a la zona sobre la que se iba a desencadenar la ofensiva de 1937 que acabaría con la toma de Bilbao y Santander. Fueron realizadas con extraordinaria celeridad durante el verano de 1937 , y en circunstancias particularmente difíciles: debieron ser dibujadas a partir de documentos heterogéneos y poco apropiados, ya que el Instituto Geográfico todavía no había publicado la mayor parte de las hojas correspondientes al sector. El resultado, en algunos casos, son poco más que bocetos, en los que la altimetría está incompleta. Sin embargo, tales bocetos tenían una crucial importancia, ante la ausencia de cartografía más precisa (ver figura 2). A finales de junio de 1937 el Corpo di Truppe Volontarie disponía ya de ejemplares impresos de las hojas 34 (Torrelavega), 35 (Santander) y 58 (Los Corrales de Buelna), y la sección cartográfica realizó una tirada adicional de 1.000 copias con destino al Cuartel General de Franco ${ }^{17}$.

Entre octubre y diciembre de 1937 los cartógrafos italianos trabajaron en un conjunto de una docena de hojas relativas a la zona norte y nordeste de Madrid, incluyendo la capital (ver figura 3). En este caso la revisión fue bastante cuidadosa, empleándose para ello fotografías aéreas. La hoja de Madrid, que carece de identificación numérica, se preparó con un especial cuidado. Tiene un formato de $59 \times 79 \mathrm{~cm}$, incluyendo como rebase parte de las hojas adyacentes. Se imprimió a cinco colores, realizándose una tirada de 3.000 ejemplares. Al margen se indica la fecha y lugar de impresión: Vitoria, 18 de diciembre de 1937.

El Corpo di Truppe Volontarie, sin embargo, no iba a entrar en combate en Madrid. Su destino en la primavera de 1938 fue el frente de Aragón, y más tarde la región levantina. A lo largo de 1938 la sección topocartográfica dibujó y grabó un nutrido grupo de hojas correspondientes al área central del valle del Ebro, y unas pocas correspondientes a la zona de Teruel. A finales de aquél año, a medida que se acercaba la ofensiva sobre Cataluña, la compilación de la serie italiana fue prácticamente abandonada. Los italianos paralizaron la edición de su «Carta della Spagna» y concentraron su trabajo en reforzar la capacidad de producción de los servicios de cartografía del Cuartel General de Franco. Durante la operaciones realizadas en Cataluña la sección cartográfica italiana imprimió 70.000 copias del mapa a escala 1:50.000, correspondientes a un grupo de hojas cuyos originales habían sido preparados por los cartógrafos militares españoles.

El mapa topográfico a escala 1:50.000 constituyó la base cartográfica para buena parte de la cartografía de menor escala empleada en la guerra civil. A partir del 1:50.000 se obtuvieron nuevos mapas por reducción, o se derivó la información para obtener mediante generalización cartas de escala menor. Entre los mapas formados por reducción destaca el Mapa de Mando a escala 1:100.000, del cual el servicio cartográfico de Franco editó un centenar de hojas.

17 ISTITUTO GEOGRAFICO MilitARE: op. cit., 1939, pág. 20.

Hispania, LXII/1, núm. 210 (2002) 283-298 
OBBIETTIVI DEL BOMBARDAMENTO AEREO IN FASE DI PREPARAZIONE

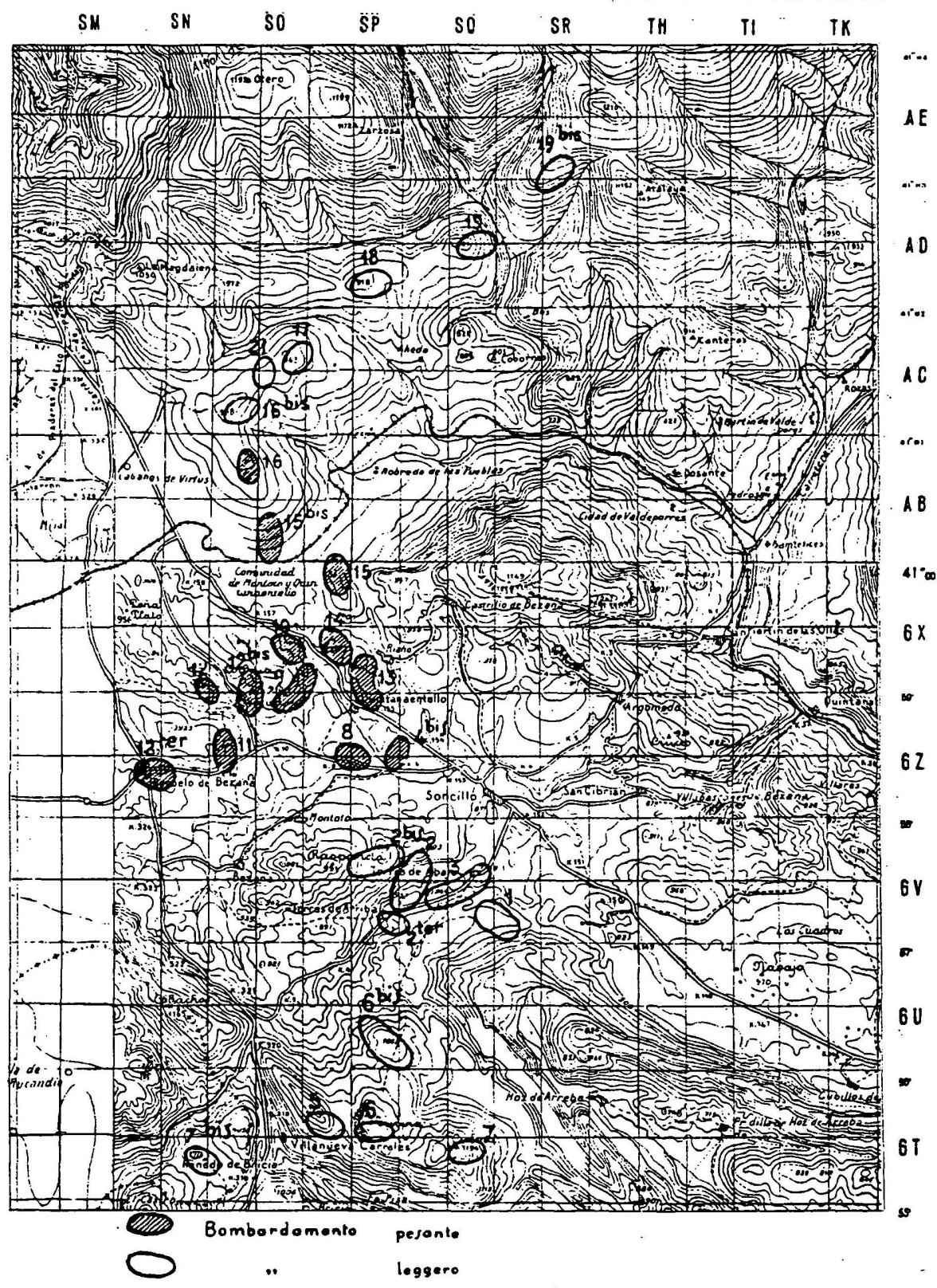

Figura 2. Detalle de una de las hojas del 1:50.000 distribuidas para la batalla de Santander. Se indican los objetivos de bombardeo «ligero» y «pesado".

Fuente: La Sezione Topocartografica dell Instituto Geografico Militare in terre di Spagna con el Corpo Truppe Volontarie, 1939.

Hispania, LXII/1, núm. 210 (2002) 283-298 
La actividad de la Sezione Topocartografica respecto al mapa a escala 1:100.000 fue reducida, limitándose a la formación y publicación de nueve hojas. Hemos podido localizar seis hojas de este grupo, que carecen de identificación numérica, y cuentan con la siguiente identificación nominal: «Gijón», "Guadalajara», «Brihuega», «Chelva», «Zuera»y «Madrid e dintorni. Foglio Nord».

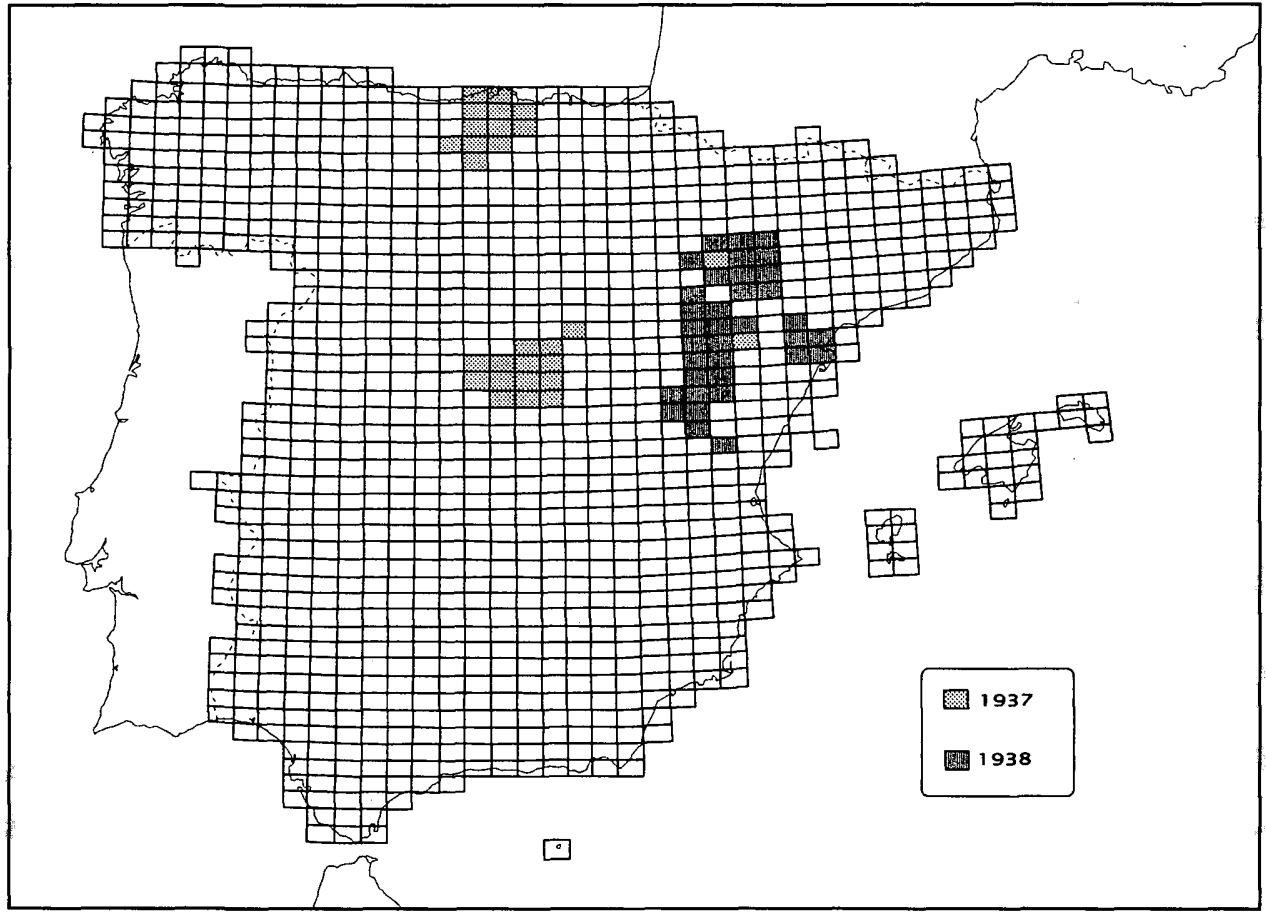

Figura 3. Distribución de las hojas a escala 1:50.000 redibujadas por la Sezione Topocartografica en 1937 y 1938.

Fuente: Elaboración propia.

La hoja correspondiente a Gijón fue la primera en realizarse (durante el verano de 1937) y es un caso especial. Pese a que el Instituto Geográfico había culminado ya el levantamiento topográfico en la mayor parte del litoral asturiano, al comenzar la guerra aún no se había publicado ninguna de las hojas correspondientes a la zona. En consecuencia, los cartógrafos italianos debieron trabajar a partir de fuentes diversas, que no se especifican, para obtener la planimetría. En cuanto a la altimetría la solución fue realmente atípica: se figuró mediante normales. El resto de las hojas citadas se obtuvieron, en cada caso, por reducción fotomecánica de cuatro hojas del 1:50.000, que habían sido previamente redibujadas. 


\section{LA CARTA ITINERARIA A ESCALA 1:200.000 CON TINTAS HIPSOMÉTRICAS}

El Ejército español disponía en 1936 de un mapa itinerario a escala 1:200.000, cuya edición estaba casi completa: faltaban tan sólo por aparecer las hojas correspondientes a las islas Baleares. Sin embargo, el Mapa Militar Itinerario de España, cuya formación se había iniciado en 1880, tenía un limitado interés cuando estalló la guerra. La primera edición de la carta itineraria carece de altimetría, y las transformaciones de las vías de comunicación durante las tres primeras décadas del siglo XX habían arruinado su utilidad como mapa de carreteras. El Depósito de la Guerra había iniciado la modernización del mapa en 1929, con una nueva edición con altimetría por medio de curvas de nivel de 50 en 50 metros y sombreado. Hasta 1936 se habían conseguido imprimir tan sólo cuatro hojas de la edición moderna con altimetría, sobre un total previsto de $65^{18}$. En consecuencia, la actualización y modernización del mapa itinerario suponía un auténtico reto para los Estados Mayores, y especialmente para las tropas italianas.

Uno de los rasgos esenciales de la fuerza expedicionaria italiana era su carácter de fuerza motorizada, capaz de desplegarse con notable rapidez. La cartografía itineraria constituía así una necesidad particularmente sensible para el Corpo di Truppe Volontarie. La Sezione Topocartografica había adoptado las mismas soluciones que el servicio cartográfico del Ejército de Franco para proveerse de cartografía a escala 1:50.000: reproducir las hojas del Mapa topográfico de España, respetando su formato y su cuadro de distribución, aunque redibujándolas con su propio estilo. En el caso de la cartografía itineraria las soluciones fueron distintas.

El servicio cartográfico de Franco otorgó una atención secundaria al Mapa Militar Itinerario a escala 1:200.000, poniendo mayor interés en la reproducción de un mapa de carreteras a escala 1:400.000, que fue compilado en el curso de la guerra ${ }^{19}$. Los italianos, por el contrario, pusieron la carta 1:200.000 en el centro de su interés. En septiembre de 1937 habían decidido ya compilar un nuevo mapa a la citada escala, que debía editarse en policromía, representando el relieve mediante curvas de nivel equidistantes 100 metros y tintas hipsométricas ${ }^{20}$. La carta debía derivarse del Mapa topográfico a escala 1:50.000, adoptando un formato de hoja de $81 \times 56 \mathrm{~cm}$, que era el formato máximo que admitían los medios de reproducción disponibles. Con tal formato cada hoja del 1:200.000 comprendía 36 hojas del 1:50.000, representándose una zona de terreno de 1 grado de latitud por 2 de longitud. Las hojas debían incorporar una retícula geográfica de $10^{\prime}$ de latitud por $20^{\prime}$ de longitud.

\footnotetext{
18 García-BAQUero y SÁEnZ de Vicuña, Manuel, Historial del Mapa Itinerario Militar español, Madrid, Servicio Geográfico del Ejército, 1985, pág. 89.

19 CuARTel General del Generalísimo, op. cit., 1939.

20 Istituto Geografico Militare, op. cit., 1939, pág. 57 y ss.
} 
Al derivar el 1:200.000 del topográfico a escala 1:50.000 se producía una inevitable saturación de la información, que hacía imprescindible un proceso de generalización cartográfica. El procedimiento adoptado para formar la carta itineraria fue el siguiente. En primer lugar se realizaba una copia cianográfica del 1:50.000. Sobre tal copia se efectuaba la selección de la información que debía pasarse a la escala 1:200.000, repasando en negro los elementos a conservar. Posteriormente se practicaba una reducción de las hojas desde el 1:50.000 al 1:200.000 por medios fotográficos, revelándose luego sobre papel fotográfico indeformable («correctostat»). Una vez concluidas estas tareas preliminares se componía un mosaico fotográfico con las hojas reducidas hasta formar la hoja del 1:200.000. A partir del citado mosaico se elaboraban las planchas para la impresión a color. Los colores de impresión eran negro para la planimetría, azul para la hidrografía, rojo para las carreteras principales y siena para la orografía.

La primera hoja del mapa itinerario, denominada "Zaragoza-Lérida», se publicó el 28 de octubre de 1937, tras poco más de un mes de trabajo febril. Le seguirían 12 hojas más (ver figura 4), que fueron apareciendo en función de las necesidades más urgentes, o de las previsiones estratégicas, del Corpo di Truppe Volontarie. La Sezione Topocartografica trabajó dia y noche durante el mes de febrero de 1938 para preparar la hoja "Teruel-Tortosa», cuyas primeras copias fueron entregadas a los mandos del Corpo di Truppe Volontarie el 7 de marzo, tan sólo unas horas antes de que se iniciase la campaña que culminaría con el corte de las líneas republicanas en Castellón ${ }^{21}$. En los meses de abril y mayo de 1938 se editaron, respecticamente, las hojas de "Valencia» y «Tarragona-Barcelona». En ambos casos la Sezione Topocartografica trabajó contrarreloj, acuciada por un Estado Mayor que preveía, infundadamente, un rápido hundimiento del frente republicano. Las hojas restantes, correspondientes en su mayoría al sector central de la Península, se prepararon, ya con menos premura, a lo largo de la segundo semestre de 1938 y los primeros meses de 1939.

El mapa italiano a escala 1:200.000 se concibió inicialmente como carta itineraria: el empeño puesto en la correcta representación de las vías de comunicación respondía, primariamente, a las necesidades de las unidades motorizadas. Sin embargo, su uso iba a ser mucho más amplio. El 15 de noviembre de 1937 el coronel Wolfram von Richtofen, jefe de Estado Mayor de la Legión Cóndor, se dirigió al Corpo di Truppe Volontarie para solicitar 250 ejemplares de la hoja Zaragoza-Lérida. Justificaba su petición señalando que el 1:200.000 eran el único mapa que podía servir a sus pilotos "para tareas de información ${ }^{22}$. El interés de von Richtofen por el mapa italiano es explicable. Aunque los planes ordenadores de vuelo solían trazarse sobre el mapa a escala 1:50.000, la mala legibilidad de las hojas disponibles en impresión monocroma

21 ISTITUTO GeOGrafico Militare, op. cit., 1939, pág. 72.

22 ISTITUTO GEOGRAFICO MilitARE, op. cit., 1939, pág. 65. 
reducía mucho su utilidad como mapa de aproximación, o en las labores de reconocimiento. Los aviadores alemanes, y los italianos, preferían las hojas en policromía del 1:200.000, que habían sido descargadas de detalles topográficos innecesarios, y acentuaban la representación de los ejes de comunicación que podían ser identificados con facilidad desde el aire.

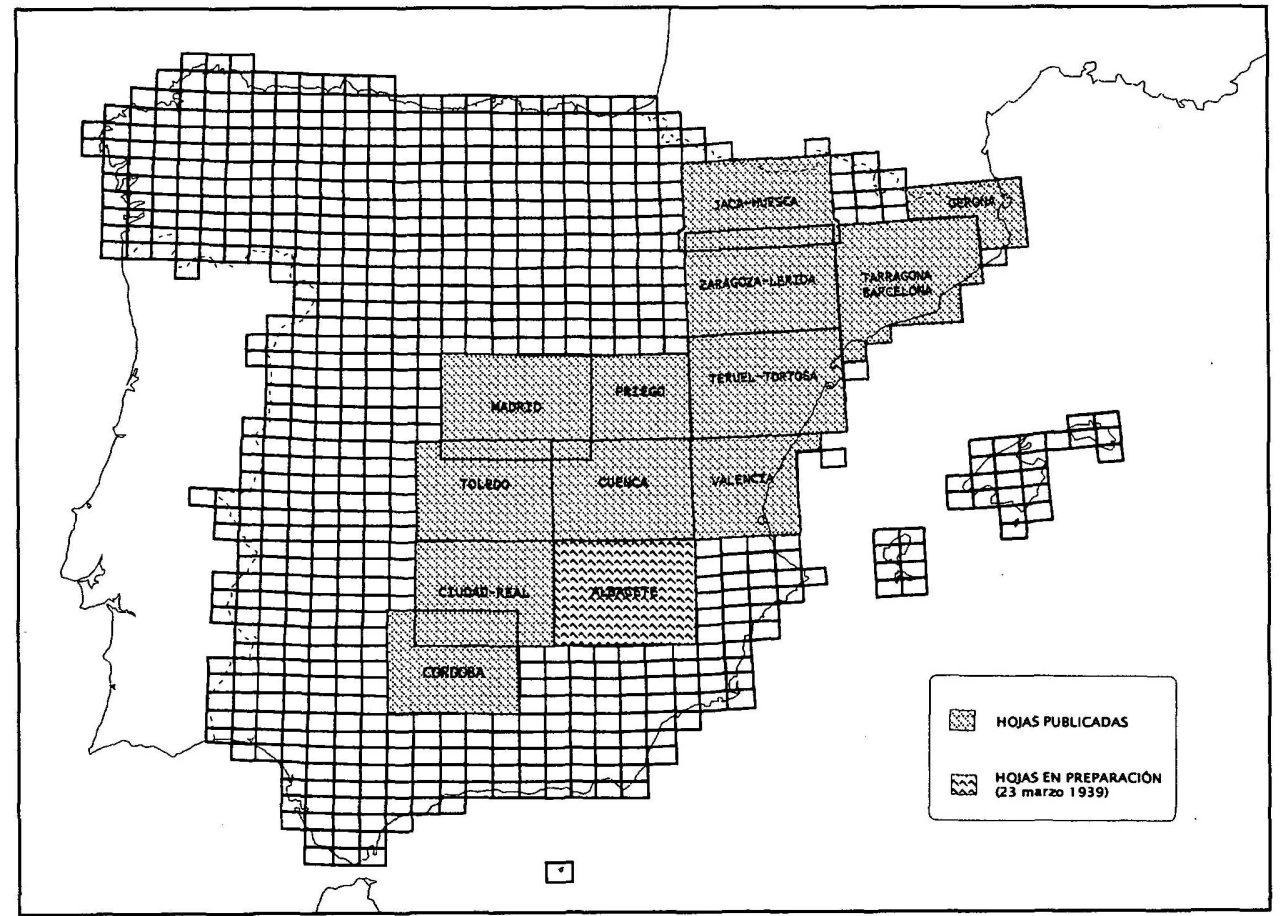

Figura 4. Distribución de las hojas de la carta itineraria a escala 1:200.000 con tintas hipsométricas.

Fuente: Elaboración propia.

Un claro indicio de la importancia del mapa a escala 1:200.000 es el tiraje del mismo. La tirada media de las hojas de la carta itineraria fue ligeramente superior a los 4.000 ejemplares (ver cuadro 1). Se trata de una cifra muy importante considerando que estamos ante un mapa en color, cuyo coste de reproducción era muy superior al de los mapas monocromos. En cualquier caso, el tiraje de la carta itineraria superó ampliamente en promedio al de cualquiera de los otros mapas impresos por la Sezione Topocartografica. Una simple comparación entre la actividad editorial de la sección italiana y la acción paralela de la Sección Cartográfica del Ejército de Franco puede resultar reveladora. El servicio cartográfico franquista imprimió 35 hojas del Mapa Militar Itinerario a 
escala 1:200.000, con una producción litográfica total de 135.724 ejemplares, pero con una tirada promedio inferior a la del Corpo di Truppe Volontarie ${ }^{23}$.

\section{CUADRO 1}

Cartografía impresa por la «Sezione Topocartográfica» desde mayo de 1937 a abril de 1939

\begin{tabular}{||l|c|c|c||}
\hline \hline ESCALA DE LOS MAPAS & $\begin{array}{c}\text { No }^{\circ} \\
\text { IME ORIGINALES }\end{array}$ & $\begin{array}{c}\text { TIRADA MEDIA POR } \\
\text { HOJA }\end{array}$ & TIRADA TOTAL \\
\hline $1: 50.000$ & 290 & 1.237 & 358.890 \\
\hline $1: 100.000$ & 22 & 2.324 & 51.130 \\
\hline $1: 200.000$ & 13 & 4.027 & 52.350 \\
\hline Otros documentos* & 172 & 251 & 43.265 \\
\hline Total & 497 & & 505.635 \\
\hline
\end{tabular}

(*) Croquis topográficos, cuadros de distribución, etc.

Fuente: Elaboración propia a partir de Istituto Geografico Militare, 1939.

En conjunto, la Sezione Topocartografica puso en circulación algo más de medio millón de impresos de mapas a diversas escalas. La parte más importante, un 70\%, corresponde a la edición de 230 hojas del mapa 1:50.000 (60 hojas de la serie italiana, y 230 de una colección preparada por el servicio cartográfico franquista). El 30\% restante se divide, casi a partes iguales, entre el Mapa de Mando, la carta itineraria a escala 1:200.000, y un conjunto heterogéneo de documentos que incluye croquis topográficos, gráficos de distribución de las hojas de distintos mapas, y otros elementos menores. Esta considerable producción equivale aproximadamente a un $17 \%$ de la producción cartográfica total de los servicios cartográficos del Ejército de Franco.

\section{CONCLUSIÓN}

La Sezione Topocartografica llegó a España tras la batalla de Guadalajara. Es decir, una vez que el Alto Mando italiano decidió reestructurar el Corpo di Truppe Volontarie, desde la clara conciencia de que la guerra contra la República no iba a ser un paseo militar. El envio desde Italia de una unidad de cartógrafos militares experimentados, con un completo equipo listo para la reproducción de mapas, constituye una evidencia más del crucial apoyo prestado por Mussolini a la victoria del general Franco. También pone de relieve, retrospec-

23 Cuartel General Del Generalísimo, op. cit., 1939. 
tivamente, la pobreza de medios cartográficos con la que debieron desenvolverse la fuerzas insurrectas durante los primeros meses de la guerra.

La actividad de los cartógrafos italianos fue relevante, tanto en términos cuantitativos como cualitativos. La Sezione Topocartografica imprimió más de medio millón de mapas a distintas escalas, que fueron distribuidos tanto al Corpo di Truppe Volontarie como a otras unidades de las fuerzas franquistas. Los italianos realizaron un efectivo rediseño del Mapa Topográfico de España a escala 1:50.000, y llevaron a término un cuidadoso trabajo de generalización cartográfica para obtener la carta itineraria a escala 1:200.000. En términos generales, los mapas italianos resultan formalmente más cuidados que los compilados por otros servicios cartográficos.

Los recursos y capacidad operativa de la Sezione Topocartografica dejaron una positiva impresión entre los cartógrafos militares españoles. Cabe citar, en este sentido, el testimonio del comandante de Estado Mayor Carmelo Medrano, que actuó como brazo derecho del general Franco en el Cuartel General durante el curso de la guerra. El 1 de abril de 1939 el comandante Carmelo Medrano, firmaba un informe dirigido al Ministro de Defensa exponiendo la urgente necesidad de reorganizar el servicio cartográfico del Ejército. Su ideal era inequívoco: «Puede citarse como modelo de organización del Servicio Cartográfico Militar el que posee actualmente Italia, cuya residencia es en Florencia, con sus cinco divisiones o secciones: Geodesia, Topografía, Cartografía, Artística, de Revisión fototécnica y de Ampliaciones, sin estar sometido a la servidumbre de talleres a que se encontraba nuestro Servicio Geográfico con anterioridad al Movimiento» 24 .

La intervención de la Sezione Topocartografica marca un punto de inflexión en la historia de la cartografía española: el inicio de su internacionalización. Hasta la guerra civil los mapas de España a gran escala han sido realizados, para bien o para mal, por organismos de la Administración española. Esta situación cambiará radicalmente en el medio siglo siguiente. El destino de las hojas compiladas por los cartógrafos italianos fue ciertamente singular. En primer término fueron aprovechadas por el Estado Mayor alemán para formar, entre 1940 y 1945, la Deutsche Heereskarte. Spanien 1:50.000. Posteriormente, un cierto número de aquellas hojas serían reaprovechadas de nuevo por el Army Map Service de los Estados Unidos para compilar la primera edición de su colección Spain 1:50.000. Series M781-M788.

\footnotetext{
21. Medrano, Carmelo, «Necesidad de un proyecto de reorganización del Servicio Cartográfico Militar», en Cuartel General del Generalísimo, op. cit., 1939, Anexo 2, págs. 1-3.

Hispania, LXII/1, núm. 210 (2002) 283-298
} 